\title{
Erratum to: Marker assisted backcross breeding approach to improve blast resistance in Indian rice (Oryza sativa) variety ADT43
}

\author{
Balakrishnan Divya $\cdot$ S. Robin $\cdot$ R. Rabindran • \\ N. Senthil $\cdot$ M. Raveendran $\cdot$ A. John Joel
}

Published online: 4 July 2014

(C) Springer Science+Business Media Dordrecht 2014

\section{Erratum to: Euphytica DOI 10.1007/s10681-014-1146-9}

Due to an unfortunate turn of events, the fourth author's name appeared incorrectly in the original

The online version of the original article can be found under doi:10.1007/s10681-014-1146-9.

\section{B. Divya · A. J. Joel}

Department of Plant Genetic Resources, Centre for Plant Breeding and Genetics, Tamil Nadu Agricultural University, Coimbatore 641003, India

e-mail: jnjoel@gmail.com

\section{B. Divya $\cdot$ S. Robin}

Department of Rice, Centre for Plant Breeding and Genetics, Tamil Nadu Agricultural University,

Coimbatore 641003, India

e-mail: robin.tnau@gmail.com

B. Divya $(\bowtie)$

ICAR-National Professor Project, Crop Improvement Section, Directorate of Rice Research-ICAR, Hyderabad, India

e-mail: divyabalakrishnan05@gmail.com

R. Rabindran

Department of Plant Pathology, Centre for Plant

Protection Studies, Tamil Nadu Agricultural University,

Coimbatore, India

e-mail: rabinr1956@gmail.com publication and should have read N. Senthil. The correct representation of the authors' names is listed above and should be treated as definitive by the reader.

N. Senthil

Department of Plant Molecular Biology \&

Bioinformatics, Centre for Plant Molecular Biology and

Biotechnology, Tamil Nadu Agricultural University,

Coimbatore 641003, India

e-mail: senthil_natesan@yahoo.com

M. Raveendran

Department of Plant Biotechnology, Centre for Plant

Molecular Biology and Biotechnology, Tamil Nadu Agricultural University, Coimbatore 641003, India e-mail: sivakasiravi@yahoo.com 